\title{
Initiation Step of Radical Polymerization of Styrene in Various Non-Aromatic Solvents
}

\author{
Tohei Yamamoto, Jun TakeUchi, Kenji Konishi, \\ Shinji Higashika, Osamu Sangen, \\ and Mikiharu KAMACHI* \\ Faculty of Engineering, Himeji Institute of Technology, \\ Shosha, Himeji 671-22, Japan \\ * Faculty of Science, Osaka University, \\ Toyonaka 560, Japan
}

(Received September 16, 1993)

\begin{abstract}
Rates of initiation of radical polymerizations $\left(R_{\mathrm{i}}\right)$ of styrene by several initiators in non-aromatic solvents were determined and compared with those in benzene. It is considered that by forming $\pi$-complex with a geminate radical, benzene suppresses cage recombination when both are bulky, but assists it when one is small. But non-aromatic solvents show only viscosity effect and are considered to be inert-solvents.
\end{abstract}

KEY WORDS Initiation Rate / Initiation Efficiency / Tempol / Inhibitor Method / Aromatic Effect / Non-Aromatic Solvent/Cage Recombination /

Previousely we reported the dependence of initiation efficiency $(f)$ in radical polymerization of styrene (St) with azobisisobutyronitrile (AIBN) in several aromatic solvents on the viscosity of the system and monomer concentration. ${ }^{1}$ The viscosity dependence of $f$ was reported by Schulz et al. ${ }^{2}$ and Smets et al. ${ }^{3}$ as cage effect. However we found marked deviation of $f$ in carbontetrachloride ${ }^{4}$ from the relation with viscosity. ${ }^{1}$

To clarify the marked deviation, we carried out radical polymerizations of St with AIBN in various non-aromatic solvents and determined rate of initiation $\left(R_{\mathrm{i}}\right)$ by several methods. Then radical polymerizations of $\mathrm{St}$ with peroxides in benzene and cyclohexane were carried out and $R_{\mathrm{i}}$ were estimated on the basis of $R_{\mathrm{p}}$ (rate of polymerization) and known $k_{\mathrm{t}} / k_{\mathrm{p}}^{2}$.

\section{EXPERIMENTAL}

Benzene, cyclohexane, cyclohexanol, cyclo- hexanone, hexane, carbontetrachloride, methanol, and tetrahydrofuran (THF) were used as solvents. These solvents, St, AIBN, p-benzoquinone (BQ), and 4-hydroxy-2,2,6,6-tetramethylpiperidine-1-oxyl (Tempol) were commercially obtained and purified by oridinal methods. Benzoyl peroxide (BPO), cumyl hydroperoxide (CHP), $t$-butyl hydorperoxide (BHP), p-menthanhydroperoxide (MHP), dicumyl peroxide (DCP), di- $t$-butyl peroxide (DTBP), $t$-butyl cumyl peroxide (BCP) were used as initiators without further purification.

Fixed amounts of St, initiator and solvent were charged into a Pyrex glass tube or dilatometer and degassed by freezing, pumping, and thawing. After sealing under vacuum, polymerization was carried out at $60^{\circ} \mathrm{C}$. $R_{\mathrm{p}}$ was determined gravimetrically. $R_{\mathrm{i}}$ were estimated as follows: (1) inhibition method using Tempol, (2) inhibition method using $\mathrm{BQ}$, (3) from $R_{\mathrm{p}}$ and $k_{\mathrm{t}} / k_{\mathrm{p}}{ }^{2}$ obtained by $1 / P_{n}$ vs. $R_{\mathrm{p}}$ plots, (4) from the decay speed of Tempol measured by ESR with JEOL JES-FE3XG. 
The decomposition rate constant of AIBN was determined by following the volume of nitrogene produced as previously reported ${ }^{5}$ and that of peroxide was determined by following concentration iodometrically. $P_{n}$ of poly(St) were determined from the intrinsic viscosity $[\eta]$ measured in benzene at $30^{\circ} \mathrm{C}$.

\section{RESULTS AND DISCUSSION}

\section{Determination of $R_{\mathrm{i}}$}

Typical examples of $R_{\mathrm{i}}$ determination by the above 4 methods are shown in Figures $1-4$, and $R_{\mathrm{i}}$ thus obtained in benzne, cyclohexane and $n$-hexane are listed in Table I.
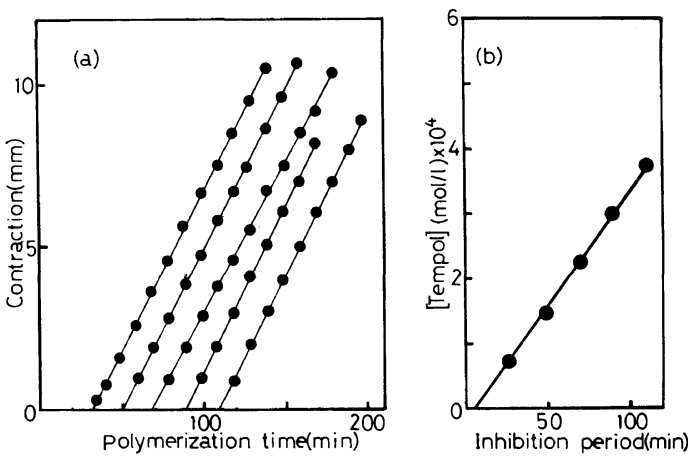

Figure 1. Measurements of inhibition periods by Tempol at $60^{\circ} \mathrm{C}$ (a) and plots of Tempol concentration against inhibition periods (b). Solvent, cyclohexane; $[\mathrm{St}]=30$ vt $\%$ : $[\mathrm{AIBN}]=6.08 \times 10^{-3} \mathrm{moll}^{-1}$.
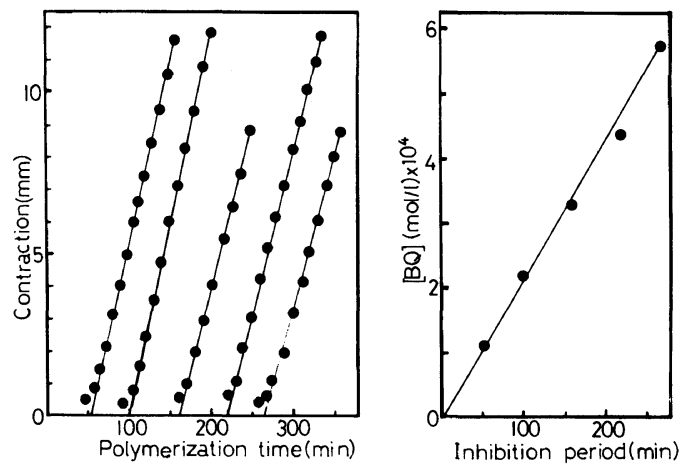

Figure 2. Measurements of inhibition periods by $p$-benzoquinone (BQ) at $60^{\circ} \mathrm{C}$ (a) and plot of $\mathrm{BQ}$ concentration against inhibition periods (b). Solvent, cyclohexane; $[\mathrm{St}]=$ $30 \mathrm{vol} \%$; [AIBN] $=6.08 \times 10^{-3} \mathrm{moll}^{-1}$.
As shown in Table I, when a solvent is absent or is benzene, $R_{\mathrm{i}}$ obtained by these methods are in good agreement. However, $R_{\mathrm{i}}$ obtained using BQ in cyclohexane and $n$-hexane are smaller than those obtained by other methods, especially at low St concentration (Table I). Although BQ is used as a suitable inhibitor for St, BQ may not catch the primary radicals quantitatively in non-aromatic solvents. Therefore Tempol was used as the inhibitor in this study and $R_{\mathrm{i}}$ obtained by using Tempol in several non-aromatic solvents are listed in Table III.

\section{Variation in $k_{\mathrm{d}}$}

To obtain $f, k_{\mathrm{d}}$ should be determined, and $k_{\mathrm{d}}$ in bulk, neat solvent and mixtures of $\mathrm{St} /$ solvent at $50 / 50(\mathrm{v} / \mathrm{v})$ were determined at $60^{\circ} \mathrm{C}$ by following the volume of nitrogen produced and listed in Table II. As shown in
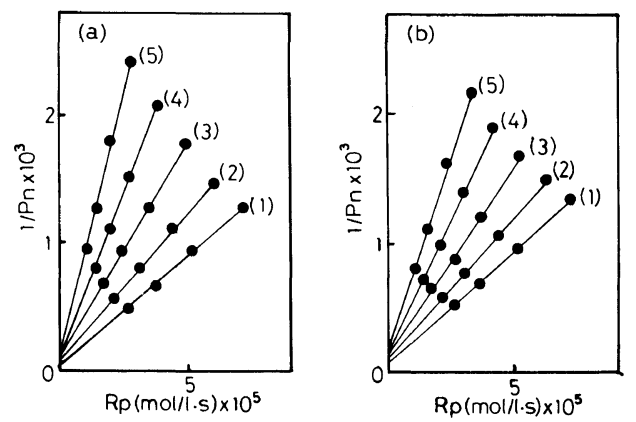

Figure 3. Plots of $1 / P_{n}$ against $R_{\mathrm{p}}$ at $60^{\circ} \mathrm{C}$ in $n$-hexane (a) and cyclohexane (b). [St] vol\%: 100, (1); 70, (2); 60, (3); 50, (4); 30, (5).
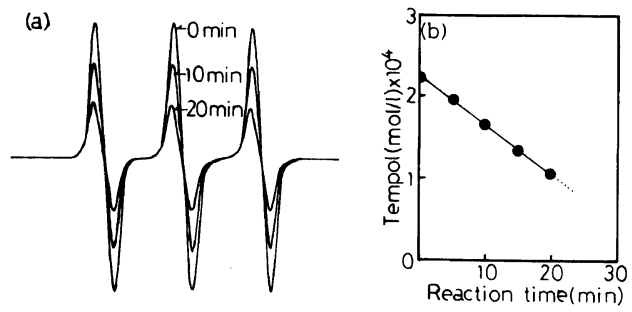

Figure 4. Variation in ESR signal of Tempol at $60^{\circ} \mathrm{C}$ (a) and plots of the Tempol concentration against the reaction time (b). Solvent, benzene; [St $]=80 \mathrm{vol} \%$; [AIBN] $=$ $6.08 \times 10^{-3} \mathrm{moll}^{-1}$. 
On the Initiation Step of Radical Polymerization

Table I. $\quad R_{\mathrm{i}}^{\mathrm{a}}$ with AIBN in benzene, cyclohexane and $n$-hexane determined by various methods at $60^{\circ} \mathrm{C}$

\begin{tabular}{|c|c|c|c|c|c|c|c|c|c|}
\hline \multirow{3}{*}{ Solvent } & \multirow{3}{*}{ Method } & \multicolumn{8}{|c|}{$R_{\mathrm{i}}\left(\mathrm{moll}^{-1} \mathrm{~s}^{-1}\right) \times 10^{8}$} \\
\hline & & \multicolumn{8}{|c|}{$[\mathrm{St}] / \mathrm{vol} \%$} \\
\hline & & 0 & 30 & 50 & 60 & 70 & 80 & 90 & 100 \\
\hline \multirow[t]{4}{*}{ Benzene } & (1) & & 7.14 & 8.17 & & 8.50 & & 9.16 & 9.36 \\
\hline & (2) & & 7.36 & 8.07 & 8.40 & 8.70 & & & 9.47 \\
\hline & (3) & & 7.6 & 8.1 & 8.4 & 8.7 & & & 9.5 \\
\hline & (4) & 6.20 & 7.50 & 8.11 & 8.33 & 8.56 & 9.06 & & 9.38 \\
\hline \multirow[t]{4}{*}{ Cyclohexane } & (1) & & 5.41 & 6.27 & & 6.94 & & 8.25 & 9.36 \\
\hline & (2) & & 4.40 & 5.70 & & 6.90 & & & 9.47 \\
\hline & (3) & & 5.8 & 6.8 & 7.2 & 7.6 & & & 9.5 \\
\hline & (4) & 2.00 & 5.40 & 6.13 & 6.63 & 6.98 & 7.39 & 8.13 & 9.38 \\
\hline \multirow[t]{4}{*}{$n$-Hexane } & (1) & & 5.67 & 6.78 & & 7.72 & & 8.50 & 9.36 \\
\hline & (2) & & & 4.70 & 5.30 & 6.50 & 7.40 & & 9.47 \\
\hline & (3) & & & 6.3 & 7.0 & 7.4 & & & 9.5 \\
\hline & (4) & 1.80 & 6.10 & 7.14 & 7.29 & 7.78 & & 8.72 & 9.38 \\
\hline
\end{tabular}

${ }^{\mathrm{a}}[\mathrm{AIBN}]=6.08 \times 10^{-3} \mathrm{mol1}^{-1}$. Experimental error, $c a . \pm 3 \%$.

Table II. Values of $k_{\mathrm{d}}{ }^{\mathrm{a}}$ of AIBN in various solvents at $60^{\circ} \mathrm{C}$

\begin{tabular}{|c|c|}
\hline Solvent & $k_{\mathrm{d}} \times 10^{5} \mathrm{~s}^{-1}$ \\
\hline St & 1.06 \\
\hline Benzene & 1.14 \\
\hline St/benzene ${ }^{b}$ & 1.08 \\
\hline Cyclohexane & 1.03 \\
\hline St/cyclohexane ${ }^{b}$ & 1.03 \\
\hline$n$-Hexane & 1.05 \\
\hline St/methanol ${ }^{b}$ & 1.21 \\
\hline $\mathrm{St} / \mathrm{THF}^{\mathrm{b}}$ & 1.40 \\
\hline St/cyclohexanone ${ }^{b}$ & 1.15 \\
\hline $\mathrm{St} /$ cyclohexanol $^{\mathrm{b}}$ & 1.26 \\
\hline $\mathrm{St} / n$-Hexane $^{\mathrm{b}}$ & 1.05 \\
\hline
\end{tabular}

a Experimental error, $c a . \pm 3 \%$.

b Mixing ratio, 50/50 (v/v).

Table II, variation in $k_{\mathrm{d}}$ was not so large and $k_{\mathrm{d}}$ in the mixture were almost the average of those in bulk and in neat solvents. So the values at the other mixing ratio were estimated by proportional distribution, and used for estimation of $f$.

Solvent Effects on $R_{\mathrm{i}}$ and $f$

$R_{\mathrm{i}}$ in the mixture of $\mathrm{St} /$ solvent $(50 / 50(\mathrm{v} / \mathrm{v}))$
Table III. $\quad R_{\mathrm{i}}$ and $f$ by AIBN in the mixture of $\mathrm{St} /$ solvent $(50 / 50 \mathrm{v} / \mathrm{v})$ and viscosity $(\eta)$ of the mixture at $60^{\circ} \mathrm{C}$

\begin{tabular}{lccc}
\hline \multicolumn{1}{c}{ Solvent } & $\begin{array}{c}R_{\mathrm{i}}^{\mathrm{a}}\left(\mathrm{moll}^{-1} \mathrm{~s}^{-1}\right) \\
\times 10^{8}\end{array}$ & $f$ & $\eta / \mathrm{cP}$ \\
\hline Benzene & 8.17 & 0.62 & 0.43 \\
$n$-Hexane & 6.78 & 0.55 & 0.32 \\
Methanol & 7.20 & 0.49 & 0.38 \\
THF & 8.32 & 0.49 & 0.42 \\
Cyclohexane & 6.27 & 0.48 & 0.48 \\
Cyclohexanone & 5.68 & 0.40 & 1.63 \\
Cyclohexanol & 4.74 & 0.31 & 2.71 \\
\hline a $\left[\right.$ AlBN] $=6.08 \times 10^{-3} \mathrm{moll}^{-1}$. Experimental error, \\
ca. $\pm 3 \%$.
\end{tabular}

are listed in Table III. As shown in Table III, $R_{\mathrm{i}}$ in these solvents are smaller than in benzene but not in THF and large values in THF are caused by large $k_{\mathrm{d}}$. The values of $f$ were caluculated from $R_{\mathrm{i}}$ and $k_{\mathrm{d}}$, and are listed in Table III. As shown in Table III, $f$ in non-aromatic solvents are smaller than in benzene.

The values of $f$ are plotted against viscosity of $\mathrm{St} /$ solvent mixture in Figure 5. As shown in 


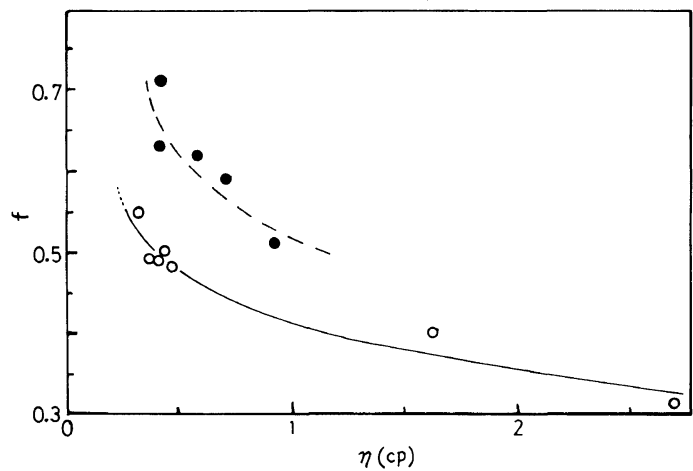

Figure 5. Relation between $f$ and $\eta$ in various solvents at $60^{\circ} \mathrm{C}$. $\bigcirc$, non-aromatic solvent; $\bigcirc$, aromatic solvent. $[\mathrm{St}]=4.36 \mathrm{moll}^{-1}(50 \mathrm{vol} \%)$.

the figure, $f$ decreased with increasing viscosity of the mixture, making a curve almost parallel to that found in aromatic solvents. These similar curves indicate that there is no marked difference between the viscosity dependence of $f$ in aromatic solvents and in non-aromatic solvents. Carbonyl compounds such as cyclohexanone did not show different influence from the other non-aromatic solvents. Hence much difference between two curves may be caused by aromatic effect.

We consider the effect as follows: Even one geminate radical makes a $\pi$-complex with an aromatic solvent molecule, as another radical may move in a different direction within the complexing time, geminate radicals have fewer chances to encounter each other, cage recombination should be suppressed in aromatic solvents, and high efficiency results in aromatic solvents. On the other hand, a non-aromatic solvent molecule does not make a complex, geminate radicals may rebound without time lag, and they have more chances to encounter each other, cage recombination should be enhanced in non-aromatic solvents, and lower efficiency results in non-aromatic solvents.

\section{Concentration Dependence of $R_{\mathrm{i}}$}

$R_{\mathrm{i}}$ obtained using Tempol in benzene, cyclohexane and $n$-hexane at several $\mathrm{St}$ concentrations (Table I) are plotted against
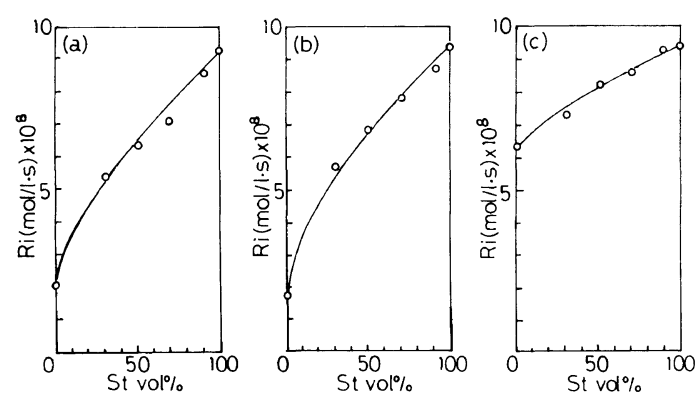

Figure 6. Dependence of $R_{\mathrm{i}}$ on monomer concentration in cyclohexane (a), $n$-hexane (b), and benzene (c) at $60^{\circ} \mathrm{C}$. $[\mathrm{AIBN}]=6.08 \times 10^{-3} \mathrm{moll}^{-1}$.

monomer concentration in Figure 6. As shown in the figure, $R_{\mathrm{i}}$ decreases with increasing solvent from the value in bulk to that in neat solvent gradually in benzene and remarkably in cyclohexane or $n$-hexane. Variation in $k_{\mathrm{d}}$ with monomer concentration is not so large. Thus, variation in $R_{\mathrm{i}}$ is caused by that in $f$ with monomer concentration.

In the figure, results in a neat solvent were obtained by method (4), because $R_{\mathrm{i}}$ in the absence of monomer could not be determined by the above methods (1)-(3). Although $R_{\mathrm{i}}=0$ in a neat solvent theoretically, the values were estimated by measuring the rate of decay of Tempol with ESR (method (4)) and are hypothetical or limiting values. The values are considered to be the rate of free radical production from geminate radical. The difference between the value in neat benzene and in neat cyclohexane or neat hexane is considered the aromatic effect. Then the difference between the value in bulk and that in neat benzene is considered to be the monomer effect, and $\mathrm{St}$ has both aromatic and monomer effects. $R_{\mathrm{i}}$ dependence on $[\mathrm{St}]$ appeared as a combination of these effects.

\section{Polymerization with Peroxide}

$R_{\mathrm{p}}$ obtained in benzene and cyclohexane using various peroxides at $60^{\circ} \mathrm{C}$ are listed in Table IV. Of course they were obtained by deduction of pure thermal polymerization rate from total polymerization rate. $R_{\mathrm{i}}$ were 
Table IV. $R_{\mathrm{p}}{ }^{\mathrm{a}}$ and $R_{\mathrm{i}}{ }^{\mathrm{b}}$ with various peroxides in benzene and cyclohexane at $60^{\circ} \mathrm{C}$

\begin{tabular}{|c|c|c|c|c|c|}
\hline \multicolumn{2}{|c|}{ Initiator } & \multicolumn{2}{|c|}{$R_{\mathrm{p}}\left(\mathrm{moll}^{-1} \mathrm{~s}^{-1}\right) \times 10^{6}$} & \multicolumn{2}{|c|}{$R_{\mathrm{i}}\left(\mathrm{moll}^{-1} \mathrm{~s}^{-1}\right) \times 10^{9}$} \\
\hline & {$[\mathrm{I}]\left(\mathrm{moll}^{-1}\right) \times 10^{2}$} & Benzene & Cyclohexane & Benzene & Cyclohexane \\
\hline AIBN & 0.62 & 24.53 & 23.08 & 77.7 & 67.4 \\
\hline CHP & 1.86 & 4.56 & 6.93 & 2.69 & 6.07 \\
\hline ВHP & 1.84 & 3.57 & 3.76 & 1.65 & 1.80 \\
\hline MHP & 1.83 & 5.18 & 5.49 & 3.50 & 3.82 \\
\hline DCP & 1.82 & 2.14 & 2.10 & 0.59 & 0.56 \\
\hline DTBP & 1.82 & 1.36 & 1.26 & 0.24 & 0.20 \\
\hline BPO & 0.86 & 14.88 & 19.47 & 28.7 & 48.0 \\
\hline $\mathrm{BCP}$ & 1.83 & 2.37 & 2.09 & 0.73 & 0.55 \\
\hline
\end{tabular}

a $[\mathrm{St}]=4.36 \mathrm{moll}^{-1}(50 \mathrm{vol} \%)$.

b Derived from $R_{\mathrm{p}}$ and $k_{\mathrm{t}} / k_{\mathrm{p}}{ }^{2}$ (1230 for benzene, 1200 for cyclohexane).

Table V. Values of $k_{\mathrm{d}}$ of BPO and CHP in benzene and cyclohexane at $60^{\circ} \mathrm{C}^{\mathrm{a}}$

\begin{tabular}{ccc}
\hline & $k_{\mathrm{d}}$ in benzene & $k_{\mathrm{d}}$ in cyclohexane \\
\hline BPO & $0.22 \times 10^{-5}\left(\mathrm{~s}^{-1}\right)$ & $0.95 \times 10^{-5}\left(\mathrm{~s}^{-1}\right)$ \\
CHP & $0.60 \times 10^{-7}\left(\mathrm{~s}^{-1}\right)$ & $0.50 \times 10^{-5}\left(\mathrm{~s}^{-1}\right)$ \\
\hline
\end{tabular}

a These values were determined iodometrically in the absence of styrene.

calculated from $R_{\mathrm{p}}$ and $k_{\mathrm{t}} / k_{\mathrm{p}}{ }^{2}$ (1230 for benzene and 1200 for cyclohexane) and are listed in Table III. As shown in Table IV, when hydroperoxide was used, $R_{\mathrm{i}}$ in cyclohexane was larger than in benzene, but with di-peroxide except BPO, $R_{\mathrm{i}}$ in benzene was larger than in cyclohexane.

The values of $k_{\mathrm{d}}$ of the peroxides were not obtained in the presence of $\mathrm{St}$ at $60^{\circ} \mathrm{C}$. Thus, it is difficult to discuss differences between $R_{\mathrm{i}}$ in benzene and cyclohexane. However, $k_{\mathrm{d}}$ of BPO and CHP could be determined in neat benzene and cyclohexane and are listed in Table V. Variation in $R_{\mathrm{i}}$ is discussed on the basis of $k_{\mathrm{d}}$.

We assumed the following: (a) The influence of St on $k_{\mathrm{d}}$ of peroxide is similar in benzene and cyclohexane. (b) Variation in $k_{\mathrm{d}}$ of other di-peroxides with a solvent is similar to that of BPO. (c) Variation in $k_{\mathrm{d}}$ of other hydroperoxides is similar to that of CHP. Thus, when di-peroxide is used as an initiator, $f$ in benzene is larger than that in cyclohexane. When hydroperoxide is used as an initiator, $f$ in benzene is smaller than in cyclohexane. We considered the reason as follows: When di-peroxide which produces bulky radicals is used, bulky radicals do not diffuse so fast but benzene retards cage recombination. When hydroperoxide which produces a bulky radical and a small hydroxyl radical is used, the small radical cannot diffuse faster in benzene than in cyclohexane because of $\pi$-complex formation.

\section{CONCLUSION}

Aromatic solvents play important roles in addition to viscosity effect in the initiation step of radical polymerization of styrene. When geminate radicals are bulky, aromatic solvents suppress the cage recombination by forming a $\pi$-complex with the radicals. But, when the geminate radicals are as small as the hydroxyl radical, solvents assist cage recombination by retarding rapid diffusion.

Non-aromatic solvents do not play such special roles, but show only viscosity effect and should be considered inert-solvents.

Styrene shows aromatic and monomer effects, and $R_{\mathrm{i}}$ dependence on monomer concentration is caused by variation in these effects.

The size of the primary radical is an important factor in the initiation step. 


\section{REFERENCES}

1. T. Yamamoto, T. Yamamoto, and M. Hirota, Chem. Express, 2, 663 (1987).

2. J. P. Fischer, G. Muke, and G. V. Schulz, Ber. Bunsenges. Chem. Soc., 73, 154 (1969); J. P. Fischer and G. V. Schulz, Ber. Bunsenges. Chem. Soc., 74, 1077 (1970).
3. F. Deschrijver and G. Smets, J. Polym. Sci., A-1, 2201 (1966).

4. T. Yamamoto, T. Yamamoto, M. Hirota, M. Kamachi, and S. Nozakura, Nippon Kagaku Kaishi, 1984, 774 (1984).

5. T. Yamamoto, S. Kobayashi, and T. Yamamoto, Nippon Kagaku Kaishi., 92, 1169 (1971). 